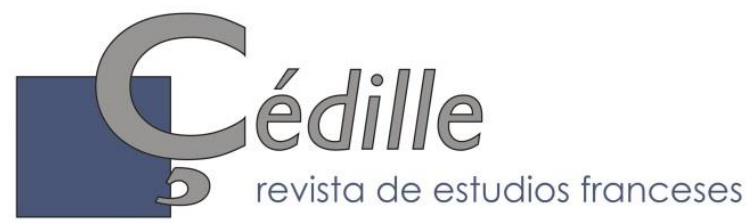

ISSN: 1699-4949

$n^{0} 18$ (otoño de 2020)

Monografías 11

Epistemocrítica: análisis literario y saber científico

Amelia Gamoneda Lanza \& Francisco González Fernández, editores científicos

\title{
Epistemocrítica: análisis literario y saber científico. Introducción
}

\author{
Amelia Gamoneda LanZa \\ Universidad de Salamanca \\ gamoneda@usal.es \\ ORCID: 0000-0002-8552-6487
}

\author{
Francisco GoNZÁLEZ \\ FERNÁNDEZ \\ Universidad de Oviedo \\ frangon@uniovi.es \\ ORCID: 0000-0002-1391-6646
}

Aunque los estudios literarios han tendido tradicionalmente a hacer abstracción del universo de los saberes científicos, resulta evidente que los poetas, novelistas y dramaturgos han dejado en sus obras, en tanto que observadores de su mundo y de su época, la huella de una imbricación científica que, visible o velada, siempre se encuentra activa. Esta huella ha llegado en algunos casos a ocupar una posición tan central que el estudio de su configuración es indispensable para poder apreciar en toda su profundidad dichas obras. En este sentido, la presencia de nociones, figuras y elementos científicos en un poema, una novela o un texto dramático no se limita a servir de decorado a acciones y sentimientos, sino que debería ser vista asimismo como injerto de componentes que modifican sustancialmente la totalidad del tejido de la obra. La empresa epistemocrítica no aspira por lo tanto a referir de forma más o menos sistemática el reflejo unívoco de tal o cual ciencia o doctrina identificable en textos concretos, como si estos fuesen meros receptáculos pasivos de ideas acabadas, sino que por el contrario concibe la escritura como una suerte de fermento de los propios saberes que moviliza. La perspectiva epistemocrítica persigue volver sensibles los efectos de un encuentro entre obra y saber, generando un tipo de lectura específica. Tal lectura no sólo vincula a las obras literarias con paradigmas y epistemes, sino que evidencia la posibilidad de instrumentación de las mismas en el ámbito de un análisis literario que no por ello renuncia a los que son sus tradicionales matices.

Originaria de Canadá y de los Estados Unidos, introducida en Francia en los años noventa del pasado siglo por Michel Pierssens, la epistemocrítica ha conocido desde entonces un importante desarrollo en el continente europeo, esencialmente en torno a la revista Epistémocritique (http://epistemocritique.org). En nuestro país, las aportaciones en esta línea de trabajo han sido sobre todo individuales y aisladas, aunque es obvio que en los últimos años se ha producido 
un incremento significativo de publicaciones relativas a la convergencia de Literatura y Ciencia (dossier especial de Quimera, de Signa, de Litoral, de El Cuaderno, de Revista de Occidente, etc.). Pero la principal actividad investigadora en el ámbito académico español con producción continuada en el campo de estudio de los modos de inscripción de la ciencia en la literatura pertenece al equipo ILICIA, vinculado con el GIR de la Universidad de Salamanca del mismo nombre-«Inscripciones Literarias de la Ciencia»-, que desarrolla proyectos de investigación en la materia desde hace diez años -todos ellos adscritos al Departamento de Filología Francesa- ${ }^{1}$.

En esta monografía de Çédille, en la que investigadores del ámbito nacional e internacional atienden a la literatura, el arte y la teoría literaria de expresión francesa, se intentará cerrar el diafragma al máximo sobre el modo epistemocrítico de abordaje de textos literarios, evitando el discurso generalista sobre los acercamientos entre literatura y ciencia o la simple constatación de ideas científicas en el ámbito literario. Mayoritariamente analíticos, los artículos que aquí se presentan contienen en sí mismos la demostración activa de la diversidad de articulaciones metodológicas que contempla la epistemocrítica. Ha parecido pertinente por ello que aparezcan precedidos del texto abiertamente teórico aportado por Jesús Camarero, quien -bajo el título «El epistemotexto literario»propone una noción de «epistemotexto»-«una categoría "ficcional" y literaria del conocimiento»- que comprende variedades dependientes de las diversas modulaciones de la relación entre literatura y saberes. Ello conduce a una defensa de la función epistémica de la literatura -sin por ello desprenderla de la regencia de la teoría literaria- que la sitúa en funciones de meta-saber. La reflexión de Camarero apunta en una doble dirección: la receptividad de la literatura respecto del saber se despliega en un segundo trayecto de incidencia que alcanza a los propios saberes y a lo real. La propuesta va incluso más allá cuando se introduce la consideración de la «literatura "como" ciencia», incidiendo en los modos en los que es posible conjugar su doble condición de máthesis y poiesis. Al cabo, la literatura aparece como un «saber sobre el saber», es decir, una comprensión y una codificación particular de los saberes para las que conviene el estatuto de saber propio y cuyo objeto es «el transconocimiento literario».

En este sentido, la epistemocrítica ha de ser comprendida como ejercicio crítico de los modos del «transconocimiento», esto es, de la circulación de los saberes tanto desde el mundo real al texto literario, como de la circulación de estos saberes en el seno de los diversos niveles de la obra literaria, como de su tránsito desde la obra literaria a la recepción -que forma parte del fenómeno literario-y de su incidencia sobre los propios saberes exteriores a la literatura. Tal es la perspectiva desde la que Anne-Gaëlle Weber aborda las relaciones entre ciencia y literatura en «Pour une archéologie des usages savants du littéraire:

\footnotetext{
${ }^{1}$ Este monográfico ha sido realizado en el marco de las actividades del Proyecto de I+D de Excelencia Inscripciones literarias de la ciencia: cognición, epistemología y epistemocrítica (ILICIA) del Ministerio español de Economía y Competitividad (Ref. FFI2017-83932-P).
} 
remarques sur les présupposés d'un "literary turn"». Contrariamente a lo que pudiera sugerir una época de infatigable especialización como la nuestra, en la que al discurso literario se le niega gustosamente cualquier posible influencia sobre las distintas disciplinas científicas, el examen de las investigaciones realizadas en geología, biología, historia o astronomía a lo largo de los siglos XVIII y XIX revela que las formas literarias no sólo dejaron una poderosa impronta en los saberes, sino que contribuyeron incluso a su elaboración. Tres son los usos que los científicos hicieron de lo literario a la luz del estudio de Weber: el uso ornamental -consistente en apropiarse de formas retóricas o poéticas para cautivar al público y adornar el discurso científico, en contraposición a una observación sobria de los hechos-, el uso documental -que convertía la obra literaria en una prueba de la teoría- y el uso heurístico -que respondía a la necesidad de invalidar un discurso poético o mítico comúnmente admitido mediante la creación de historias contrafactuales como paso previo a la elaboración de criterios de cientificidad propios-. Estos tres usos, que podían encontrarse en un mismo texto, contribuyeron a su vez a conformar una imagen específica de la literatura, pero al mismo tiempo el estudio de este «giro literario» puso de manifiesto que los propios hombres de ciencia de aquella época estaban muy lejos de reducir las letras a un jardín de flores retóricas.

Determinante ha sido asimismo el papel que ha desempeñado la traducción en la divulgación, así como en la comunicación de ideas y conceptos de unos científicos a otros a lo largo de la historia. Lourdes Pérez González desvela en «Traductoras en el gozne del cambio de paradigma científico» la labor silenciosa y escasamente reconocida que mujeres como Madame de Châtelet, Madame Lavoisier, Mary Anne Fairfax Somerville, Ada Byron o Clémence Royer realizaron con sus traducciones. Una minuciosa exposición del discurrir de la ciencia moderna durante los siglos XVII, XVIII y XIX saca a luz el papel relevante que estas figuras tuvieron en el cambio de paradigma que acaeció en ese largo periodo en los campos de la mecánica, de la química, del cálculo y de la biología. Aunque su género no les permitía propiamente investigar, hallaron en la traducción una manera de desarrollar los conocimientos que habían adquirido de manera autodidacta y con sus trabajos contribuyeron a popularizar nociones, ideas y obras que fueron cruciales para la revolución científica aquí referida. A pesar de encontrar cerradas las puertas de la ciencia, estas mujeres desempeñaron la necesaria función de bisagra entre una lengua y otra, entre los científicos y su público. La condición femenina, que durante siglos ha imposibilitado y todavía hoy frena el acceso de tantas mujeres al mundo científico, descansa en gran medida sobre tópicos ampliamente difundidos y compartidos, pero también sobre teorías consideradas en su momento como científicas, a pesar de parecer hoy descabelladas. Como nos recuerda Pérez González, el propio Darwin estaba convencido de que el hombre difería de la mujer por su inteligencia y así lo había dejado escrito en El origen del hombre. La literatura decimonónica se nutrió de muchas de estas teorías asimilándolas en sus tramas con más o menos éxito. 
De todos los novelistas del siglo XIX, Émile Zola es sin duda quien trató más consciente y explícitamente de impregnar su obra de nociones, ideas y métodos procedentes de la ciencia. En «Les mécanismes du Naturalisme à l'épreuve: la télégonie dans Madeleine Férat», María Rodríguez Álvarez se centra en una novela muy poco conocida del jefe de filas del Naturalismo, inmediatamente anterior al ciclo de Les Rougon-Macquart, cuya trama está regida por una curiosa teoría reproductiva de la época, según la cual una mujer que ha perdido la virginidad con un hombre tendrá más adelante hijos que se parecerán a este, aunque el progenitor sea otro. El presente estudio de Madeleine Férat no se limita a referir las obras científicas de las que bebió Zola (Claude Bernard, Michelet, Varigny, etc.), pone también de manifiesto las raíces míticas de esta teoría (la mujer como molde de origen masculino: la costilla de Adán, la estatua de Pigmalión, etc.) y caracteriza esta novela como un banco de pruebas donde el escritor francés experimentó una teoría determinista científica sobre la que asentar sus ideas naturalistas y que, a pesar de haber sido rápidamente abandonada, le sirvió de ensayo general para un proyecto de mayor envergadura. Madeleine Férat vio la luz en 1868.

Tan sólo un año después, un desconocido Comte de Lautréamont, pseudónimo del no menos oscuro Isidore Ducasse, publicaba una obra tan impregnada de emanaciones científicas como pueda estarlo de agua un azucarillo. De entre las distintas disciplinas científicas que recorren Les chants de Maldoror, Mauricio Cheguhem Riani elige las matemáticas por el papel central que ocupan en esta rapsodia, pero también y sobre todo en tanto que vía real para acceder a un nuevo entendimiento del infinito que el autor franco-uruguayo compartía con los románticos. La breve historia del infinito con la que da comienzo «La domesticación del infinito: las matemáticas en Lautréamont, entre lo discreto y lo continuo» conduce a una concepción de esta noción matemática y filosófica que entronca con la imagen del océano a la que Lautréamont relacionaba con Proteo, dios del número y del logos. A la luz de este análisis, el tratamiento que el autor de Les chants de Maldoror hizo del infinito filosófico vino a anticipar dos crisis de enormes consecuencias para el mundo matemático, la del continuo, por un lado, y la de las geometrías no-euclidianas por otro; crisis, ambas, que no hacen sino recordar el seísmo que supuso el descubrimiento de los números irracionales para los pitagóricos, a los que Lautréamont aludía en su obra. El largo himno que Lautréamont dedicó a las matemáticas en su segundo canto bastó para que Léon Bloy viera en él a un matemático demente y para que Gaston Bachelard reconociera en su persona un «alma matemática».

No suele en cambio vincularse a Gustave Flaubert -que ese mismo año había publicado L'Éducation sentimentale - con la «reina de las ciencias», más bien se suele enfatizar que desde niño a este se le daba muy mal dicha disciplina. Esta es la razón que suele aducirse para explicar la singular ausencia de matemáticas en Bouvard et Pécuchet, novela en la que sin embargo convergen las demás ciencias de su época. En «Le bourdon mathématique de Flaubert», 
Francisco González Fernández recorre las principales obras narrativas del escritor, así como su correspondencia, en busca de alusiones matemáticas, que resultan inesperadamente numerosas y significantes. En el propio Bouvard et Pécuchet, tal como refrenda el estudio genético de guiones y borradores, las matemáticas no están en absoluto ausentes, sino que son objeto de un juego de ocultación que comienza desde las primeras líneas, desde la primera escena que conforma en realidad un plano geométrico de gran abstracción sobre el que paulatinamente se alza el resto del edificio narrativo. Parodiando sutilmente la pirámide del conocimiento de Auguste Comte, Flaubert convierte las matemáticas en la base de esa crítica de la razón epistémica que es su novela y en una invitación a aplicar a la lectura el rigor, la atención y la sensibilidad que le faltan a la mirada de sus dos personajes, condenándolos a un eterno fracaso.

La observación, requisito imprescindible del método experimental, adquirió una nueva naturaleza a comienzos del siglo $\mathrm{XX}$ gracias a los descubrimientos de la física cuántica. En este ámbito, el sujeto ya no se limita a observar objetivamente las propiedades de un fenómeno atómico, sino que las provoca con su acción. En «La estética cuántica: Juan Larrea, Niels Bohr y el tercero incluido», Candelas Gala se acerca a la obra del poeta vanguardista a la luz de los principios y teorías que fueron apareciendo entonces y de los que tenía buen conocimiento. Entre Heinsenberg y Niels Bohr, quien decía contemplar la existencia como un drama en el que somos a la vez espectadores y actores, y la obra de Juan Larrea se hacen patentes hondas confluencias. Especial relevancia cobra en este sentido su obra poética Versión celeste, escrita originalmente en francés porque este idioma le parecía más idóneo para expresar sus estados de conciencia «desarticulados, turbios, difíciles», una conciencia que entra así en concordancia con el principio de incertidumbre, del mismo modo que el poeta adopta el principio de complementariedad para salvar las dualidades y binarismos que han lastrado la cultura occidental. El análisis pormenorizado de este poemario, así como de su diario intelectual Orbe, evidencia que el lenguaje de Larrea responde a lo que con justicia Candelas Gala llama una «estética cuántica».

De otro orden es el procedimiento que sigue Marta Cureses a la hora de abordar las relaciones entre literatura y ciencia. En «La prosa científica de Pierre Teilhard de Chardin como texto sonoro: límites y cobordimos» adopta como hipótesis de trabajo la teoría de los cobordismos del matemático René Thom para intentar determinar un espacio «topológico» en el que formas, géneros $y$ disciplinas sigan siendo específicos y estén a la vez en estrecho contacto. La obra en la que ensaya esta hipótesis es Dilatación fonética, de Agustín González Acilu, compositor que fue pionero al plantear un trabajo en la frontera de la música y la fonética, y que en este caso tomó como material un texto científico de Teilhard de Chardin como si se tratase de un texto literario, justamente para convertirlo en texto artístico-musical. El artículo de Marta Cureses transita entre las más diversas disciplinas deteniéndose en todos aquellos aspectos (el cobordismo, el poema en prosa, el concepto de hipótesis, lo continuo y lo discontinuo, la obra científica de 
Teilhard de Chardin, el itinerario musical y vital de Acilu, el espectógrafo y otros instrumentos que desempeñaron un papel en esta corriente musical) que resultan necesarios para entender la composición referida. Al término de este recorrido la obra de Acilu aparece como un espacio donde el lenguaje científico se toca con el artístico, donde la prosa se vuelve poesía.

La contribución de Christine Baron, con título «Performativité du droit. Efficacité de la littérature et de l'image», propone -en el contexto de los estudios en Derecho y Literatura- una evaluación de los efectos de la recepción de textos narrativos y adaptaciones cinematográficas sobre las prácticas de la justicia. No se trata, sin embargo, de influencias directas en el resultado de los procesos judiciales, sino de modificaciones de percepción de la aceptabilidad de ciertas decisiones, de la modelación de un imaginario social, de la interrelación de modos enunciativos judiciales y literarios, de la creación de estados emocionales e identidades imaginarias. Con efectos proyectivos y retrospectivos, la propuesta de «encarnación del derecho» que ofrecen cine y literatura introduce modulaciones en la recepción social del ejercicio de la justicia que contribuyen a la evolución de un saber regulado e institucionalizado. $\mathrm{Y}$ es este un caso paradigmático de la reversibilidad de la práctica epistemocrítica, por la que una obra -mediante su recepción, enmarcada tanto en el ámbito social como en el fenómeno literariorevierte en un saber que le es externo la influencia estructural que de él recibió.

Uno de los niveles textuales en los cuales el análisis epistemocrítico incide de modo preferente es el estético - considerado en toda su amplitud y también en su diversidad a través de los siglos-. De este modo, por ejemplo, la poesía científica de Delille, a principios del XIX, problematiza aspectos estéticos y de composición poética a resultas de su contenido promocional, didáctico y descriptivo de las ciencias. El problema suscitado por el artículo de Hugues Marchal con título «La méthode de Virgile : sciences naturelles et ordre du texte dans la poésie de Jacques Delille», es el de la obra poética que se ve cargada de un cometido a la vez estético y epistémico. ¿Aportan los textos naturalistas de la época un orden estéticamente asumido por los poemas de Delille? Lo cierto es que -a primera vista- no parece ser el caso, pero el déficit de estructura de lo poético y su composición de fragmentos en montaje abre otra pista de impregnación epistemocrítica: la obra poética prefiere entrar en homología con la estructura del mundo y de lo viviente transmitida por las ciencias de la época, regida por modelos de organización como el diccionario de Valmont de Bomare o el coleccionismo de aficionado - modos laxos de organización y estructuración que Marchal bautiza como «el método de Virgilio»-.

La concepción estética y poética de cada momento histórico, de cada movimiento e incluso de cada autor son determinantes a la hora de localizar el nivel de la obra en el que se opera la inscripción epistemológica. Pero también el saber elige los niveles en los que inscribirse y germinar textualmente. Laurence Dahan-Gaida señala, en el estudio «Le schématisme de l'invention et la pensée morphogénétique : Paul Valéry, Gilbert Simondon, D’Arcy Thompson», la 
importancia del giro icónico y visual tanto en la cultura como en la producción de conocimiento científico: una «episteme icónica» que remonta a Kant y, en el terreno literario, tiene una importante etapa en la obra de Valéry. En torno a la noción icónico-conceptual de «esquema», el estudio reúne a la ciencia y a la literatura: del lado de la ciencia, la morfogenética -ciencia de los procesos biológicos por los que un organismo desarrolla su forma-; del lado de la literatura, el proceso de la imaginación creativa, central no solo en la temática poética de Valéry sino sobre todo en su reflexión teórica y metapoética. Ligando ciencia y literatura, el esquema expresa una regla que atañe tanto a la formación y generación de los seres vivos como a la de las ideas creativas. Si Marchal estudiaba la organización del saber sobre lo vivo en la poesía de Delille, DahanGaida estudia la fuerza formativa análoga que preside a las formaciones vivas y a la producción de las formas de la imaginación y la invención -y que, en el terreno poético, se cifra en el reconocimiento y aplicación al poema de los esquemas de crecimiento de los objetos naturales-.

La inscripción de diferentes aspectos de lo vivo en la literatura es también objeto de estudio epistemocrítico en otros artículos aquí reunidos, y entre dichos aspectos destacan los relativos a la cognición humana. De la implicación de las ciencias cognitivas en el texto literario, los textos de Víctor Bermúdez «Perception et mouvement dans la poésie de Gilles Cyr»- y Candela Salgado Ivanich - «André du Bouchet ou l'appartenance à l'air»- retienen especialmente las operaciones cognitivas ligadas a la percepción y el movimiento. A la pregunta sobre qué tipo de conocimiento manifiesta o modula el lenguaje poético, ambos artículos ofrecen respuestas analíticas particularizadas en el caso de dos poetas. Para el caso del canadiense Gilles Cyr, Bermúdez se provee de la noción de «episteme en movimiento», en la que resume un saber del poema que se resiste a coagular en concepto su cúmulo de operaciones perceptivas. El poema asume pues -en principio- las operaciones perceptivas de un sujeto, pero -en virtud de lo que llama «visión no-epistémica»- detiene toda operación de abstracción o inferencia que pudiera derivarse de aquellas. Así pues, la instrumentación de las ciencias cognitivas para el análisis poemático desvela que esta poesía localiza la especificidad de su lenguaje precisamente en la suspensión de los procesos cognitivos en el nivel de la percepción, un límite que también afecta a lo kinésico y que revela distancia entre el conocimiento inscrito en el poema y el del sujeto lírico.

En el caso del poeta du Bouchet, el análisis poético se refiere a uno de los cuatro elementos de la naturaleza: el aire. En él, Salgado Ivanich concibe una más estrecha relación entre cognición humana y cognición del poema, pues el tratamiento que el sujeto poético hace del aire revela que este adquiere formas, características, sensibilidad e intencionalidad que pertenecen en origen al propio sujeto. Pero, lejos de una personificación del elemento natural convenida y estabilizada, se trata de un proceso de construcción mutua -perceptiva, kinestésica- en el que el sujeto se ve revelado y la materia informe adquiere figura. 
Además, desde los principios de la comprensión del movimiento como acción y de la teoría de la cognición motora, el aire deviene una entidad activa que esboza el cumplimiento de las condiciones de conciencia exigidas por el hecho de ser sujeto. Así pues, el análisis cognitivo propone la poiesis de du Bouchet como pugna inexplícita entre el sujeto y objeto líricos por la condición de sujeto cognoscente.

La aplicación hermenéutica de las ciencias cognitivas presente en los dos artículos precedentes recibe una caución teórica por parte de la propuesta de Renata Gambino y Grazia Pulvirenti en «La neurohermenéutica de la sospecha. Una aproximación teórica». Inserta en el marco transdisciplinar entre Humanidades y Estudios Neurocognitivos, esta exposición articula el conocimiento ofrecido por la lectura hermenéutica a la manera de Ricœur y el ofrecido por la neurología durante la experiencia de la lectura. Pero, a diferencia de los artículos anteriores -que diseminaban en la generalidad del texto los lugares en los que prendían las operaciones cognitivas-, aquí se defiende que la construcción del sentido posee claves inferenciales residentes en elementos estilísticos y retóricos puestos de relieve (localizables mediante una Matriz de Evaluación del Relieve desarrollada por las autoras). En este sentido, la concepción de la «hermenéutica de la sospecha»-en tanto que manifestación y restauración de significado- señala hacia un tipo de objetivos en los que, más que inventar, el lector encuentra o despliega algo que estaba oculto en la función simbólica del lenguaje -función urdida de modo cultural-. Y así pues, para abordar esa interpretación, es precisa una colaboración venida de la neurología que ponga en juego los instrumentos procedentes de la cognición sensomotora compartidos por todo lector en virtud de una «intersubjetividad» que participa en un proceso de «simulación encarnada».

La neurobiología proporciona un conocimiento científico sobre la naturaleza humana que converge con lo que hasta fechas recientes ha sido sabiduría filosófica o saber narratológico, poético y, en suma, literario. Para el caso de algunas de las etapas de la obra de Albert Camus, Amelia Gamoneda -en «La chute dans la conscience. Animalité, philosophie et cognition dans l'œuvre de Camus»- propone un acercamiento entre la conciencia del «hombre solar» camusiano -antes y después del descubrimiento del absurdo- y la concepción de diversos grados de conciencia que proporcionan las actuales teorías neurobiológicas. La consideración de una conciencia cercana a la del animal, para la que «el juicio del cuerpo es más determinante que el de la mente», permite una lectura cognitiva de episodios de L'Étranger que distingue momentos de articulación entre diferentes tipos de conciencia, al tiempo que proporciona los elementos para el análisis de ecos y contrastes entre interrogantes morales presentes en las diversas etapas de la obra camusiana. Y así pues, esta lectura epistemocrítica viene a refrendar el «instinto científico» de esa literatura que se ha interrogado sobre la conciencia desde principios del siglo $\mathrm{XX}-\mathrm{y}$ de la que son exponentes Proust o Woolf, por no citar más que dos ejemplos señeros-. 
La nómina de los artistas y escritores mencionados, la variedad de las disciplinas y la pluralidad de los enfoques adoptados en este número monográfico constituyen una excelente muestra del enriquecimiento que puede aportar un enfoque epistemocrítico, tanto a las humanidades como a las ciencias. Los modos de convergencia entre saberes y literatura considerados desde esta perspectiva contribuyen a interrogar la verdadera naturaleza de las disciplinas, cuestionan las ideas recibidas, reconsideran las fronteras artificialmente trazadas y aportan una dimensión adicional que pasa normalmente desapercibida al observar la realidad o al contemplar los discursos artísticos o científicos. 